\title{
Trabalho, educação e transformação social: elementos para a elaboração de um
}

\section{projeto alternativo}

\author{
Work, education and social transformation: elements for the preparation of an alternative project \\ Trabajo, educación y transformación social: elementos para la preparación de un proyecto \\ alternativo
}

Recebido: 04/02/2021 | Revisado: 07/02/2021 | Aceito: 11/02/2021 | Publicado: 17/02/2021

\author{
Jessyca Barbosa Duarte \\ ORCID: https://orcid.org/0000-0003-3844-7601 \\ Universidade Federal do Ceará, Brasil \\ E-mail: jessycabarbosa75@hotmail.br \\ Renata Maria Paiva da Costa \\ ORCID: https://orcid.org/0000-0003-2195-0104 \\ Universidade Federal do Ceará, Brasil \\ E-mail: renatampc5@gmail.com \\ Richelly Barbosa de Medeiros \\ ORCID: https://orcid.org/0000-0002-8243-7331 \\ Universidade Federal do Ceará, Brasil \\ E-mail: richellybarbosa@ufc.br
}

\begin{abstract}
Resumo
O presente artigo tem como objetivo expor a centralidade do trabalho como categoria fundante dos modelos de práxis social e abordar a educação como um complexo direcionado para a sociedade, isto é, inserida na reprodução das relações sociais, nas quais os homens influenciam as ações de outros homens. Compreendendo a educação como um por teleológico secundário, esta pode servir como veículo de manutenção da ordem hegemônica do capital. Na sociedade burguesa, o trabalho é capturado, a fim de atender às necessidades de acumulação de lucros; para tal, a educação seria fundamental, uma vez que forneceria não só o conhecimento científico para a produção das mercadorias, mas também seria instrumento de disseminação do ethos burguês. Para dar conta dessas análises, refletindo sobre uma possível alternativa a essa educação capitalista, este estudo se caracterizou, quanto aos objetivos, como exploratório, tendo sido, quanto aos procedimentos, embasado por revisão bibliográfica, que ocorreu em referenciais teóricos de aporte marxista. Portanto, a partir das análises teórico-metodológicas desenvolvidas, foi possível concluir que a construção de uma educação, de fato, emancipatória exigiria transformações societárias profundas, que fossem capazes de superar os mais diversos processos de alienação e de exploração de homens e de mulheres.
\end{abstract}

Palavras-chave: Trabalho; Educação no capitalismo; Transformação social.

\begin{abstract}
This article aims to expose the centrality of work as a founding category of social praxis models and approach education as a complex directed towards society, that is, inserted in the reproduction of social relations, in which men influence actions of other men. Understanding education as a secondary teleological, it can serve as a vehicle for maintaining the hegemonic order of capital. In bourgeois society, labor is captured in order to meet the needs of accumulating profits; to this end, education would be fundamental, since it would provide not only scientific knowledge for the production of goods, but would also be an instrument for the dissemination of bourgeois ethos. To account for these analyzes, reflecting on a possible alternative to this capitalist education, this study was characterized as exploratory and based on a bibliographic review, which occurred in theoretical references of Marxist contribution. Therefore, from the theoretical-methodological analyzes developed, it was possible to conclude that the construction of an education, in fact, emancipatory would require profound societal transformations, which would be able to overcome the most diverse processes of alienation and exploitation of men and women.
\end{abstract}

Keywords: Work; Education in capitalism; Social transformation.

\section{Resumen}

Este artículo tiene como objetivo exponer la centralidad del trabajo como categoría fundacional de los modelos de praxis social y abordar la educación como un complejo dirigido a la sociedad, es decir, inserta en la reproducción de las relaciones sociales, en las que los hombres influyen en las acciones de otros hombres. Entendiendo la educación como un poner teleológico secundario, ésta puede servir como vehículo para mantener el orden hegemónico del capital. En la sociedad burguesa, el trabajo está capturado para satisfacer las necesidades de acumulación de 
ganancias; para ello, la educación sería fundamental, ya que proporcionaría no solo conocimientos científicos para la producción de bienes, sino que también sería un instrumento para la difusión del ethos burgués. Para dar cuenta de estos análisis, reflexionando sobre una posible alternativa a esta educación capitalista, este estudio se caracterizó, en términos de objetivos, como exploratorio, habiendo sido, en términos de procedimientos, basado en la revisión bibliográfica, lo que ocurrió en referencias teóricas de contribución marxista. Por lo tanto, a partir de los análisis teórico-metodológicos desarrollados, se pudo concluir que la construcción de una educación, de hecho, emancipadora, requeriría profundas transformaciones sociales, que fueran capaces de superar los más diversos procesos de alienación y explotación de hombres y mujeres.

Palabras clave: Trabajo; Educación en capitalismo; Transformación social.

\section{Introdução}

Entendermos o trabalho como categoria fundante do ser social e da práxis social é imprescindível para interpretarmos a constituição da sociabilidade e os caracteres que ela assume no decorrer das épocas e de acordo com o desenvolvimento dos meios de produção. Desse modo, o texto que se segue traz uma discussão acerca da ontologia do ser social, abordando o trabalho como base de onde emergem os modelos de práxis social, dentre estas a educação, a qual assume um viés tendente a legitimar as metas de acumulação e de obtenção de lucro no sistema capitalista de produção. Para além dessa temática, elaboramos um debate sobre a educação como categoria essencial para impetrar uma mudança radical no contexto social, orientada para a constituição de um modelo hegemônico alternativo. Para tanto, realizamos uma pesquisa bibliográfica, tomando como base para a reflexão os estudos do filósofo húngaro György Lukács, em sua obra "Para uma ontologia do ser social II", bem como o também pensador húngaro Istiván Mészáros, em "Educação para além do capital”, ambos autores marxistas.

Em um primeiro momento, abordaremos o trabalho como fundamento dos modelos de práxis, apresentando sua dimensão ontológica como categoria responsável pela (re)produção do ser social e demostrando que a partir dele surgem outros complexos, decorrentes da ação dos homens/mulheres entre si, como a educação. Por conseguinte, discutiremos como a educação passa a ser utilizada como instrumento de manutenção da ordem do capital e, por fim, quais as possibilidades de superação dessa ordem e qual seria sua influência - na formação educativa - na construção de uma sociabilidade alternativa, de caráter socialista.

Observamos, assim, que a sociabilidade do capital estabelece, estrategicamente, um conjunto de relações que objetivam perpetuar a sua existência, submetendo toda e qualquer prática humana a dar sustento às suas metas de expansão da riqueza por meio da exploração desenfreada dos indivíduos e da natureza. Percebemos, dessa maneira, que a educação, como práxis social, está organizada sobre elementos que visam viabilizar tanto o desenvolvimento de saberes e tecnologias para potencializar o processo produtivo, como a disseminação da ideologia do capital. De outro modo, podemos interpretar que a educação se apresenta como recurso fundamental para iniciar um processo de transformação social, minando as alicerces do sistema do capital.

\section{Metodologia}

Nesse estudo tivemos como objetivo investigar os elementos determinantes acerca da educação de homens e mulheres na sua relação com o trabalho e com a práxis social. Para tanto, fizemos uso de pesquisa qualitativa, dialogando com teorias e matizes do campo do marxismo e do campo das ciências da educação. O desafio versou em apreender a dinâmica mesma do objeto, sua dialética, que, para Kosik (2002, p. 34), consiste em conhecer o movimento da coisa em si, da substância que "é o movimento da coisa ou a coisa em movimento". E essa relação só é possível indo da aparência à essência das coisas, apreendendo a realidade como um todo onde residem entidades e significados - síntese de múltiplas determinações (Marx, 2011). 
O estudo, quanto aos objetivos, foi de natureza exploratória, tendo sido embasado em revisão de literatura sobre as categorias trabalho, educação no capitalismo e transformação social. Entendemos que pesquisar sobre educação reclama transcender ao específico, situando-a na sua dimensão filosófica, no contexto da formação social e histórica da sociedade, no âmbito da economia, da relação capital-trabalho-Estado, bem no que diz respeito à questão social. Desse modo, definimos por escolha teórico-metodológica a pesquisa em estudos de autores marxistas.

No caso da pesquisa bibliográfica, Gil (2002, p. 45) situa que ela possibilita ". . . ao investigador a cobertura de uma gama de fenômenos muito mais ampla do que aquela que poderia pesquisar diretamente". Essa apropriação equivale à capacidade de dialogar com fontes e pesquisas já produzidas nos campos de conhecimento que perfazem o objeto a ser estudado.

Buscamos, portanto, através da perspectiva marxista, "apreender não a aparência ou a forma dada do objeto, mas a sua estrutura e sua dinâmica (mais exatamente: para apreendê-lo como processo)". (Netto, 2011, p. 25). Ao pesquisador cabe a compreensão do real em suas múltiplas determinações, tomando por base as contradições e tendo por objetivo captar o modo de ser do objeto recortado, em meio à totalidade social, tal como partes integrantes de um complexo de complexos. É desse modo que buscamos compreender a educação na práxis social.

\section{A Categoria Trabalho como Fundamento dos Modelos de Práxis Social}

Para compreendermos a educação e sua relação com a emancipação e a superação da ordem do capital, é preciso analisar os fundamentos ontológicos do trabalho como atividade transformadora do/a homem/mulher e produtora de conhecimento. De acordo com Lukács (2013), é por meio do trabalho que se estabelece a relação entre a sociedade, o mundo orgânico e o mundo inorgânico. Deste modo, para atender as suas necessidades mais essenciais, o homem transforma a natureza, obtendo como resultado um objeto (com valor de uso) totalmente novo e diferente do seu criador, este momento é denominado por Lukács (2013) como exteriorização. O processo de objetivação ou a materialização do objeto - exteriorização pressupõe uma prévia-ideação, na qual o sujeito antevê/idealiza o que será criado. É possível que o homem ao realizar a transformação da natureza possua habilidades para manipular as propriedades que estão a sua disposição, entretanto a sua subjetividade (conhecimentos e habilidades) é confrontada com a objetividade e "por meio deste confronto, pode não apenas verificar a validade do que conhece e de suas habilidades, como também pode desenvolver novos conhecimentos e habilidades que não possuía anteriormente" (Lessa, 2015, p. 24).

$\mathrm{O}$ trabalho configura-se, portanto, como uma atividade social, uma vez que põe o homem em contato com a natureza (teleologia primária) e com outros homens (teleologia secundária), desenvolvendo, assim, novos conhecimentos. A interrelação entre homem/mulher e natureza, por meio do trabalho, demonstra o desenvolvimento da consciência, fazendo com que esta deixe de ser um mero epifenômeno. Para a construção de instrumentos necessários para a sua sobrevivência, por exemplo, o/a homem/mulher deve observar/conhecer a natureza para escolher, dentre as possibilidades que lhe são apresentadas, o material mais apropriado para tal ação. Visto assim,

A pedra escolhida como instrumento é um ato de consciência que não possui mais caráter biológico. Mediante a observação e a experiência, isto é, mediante o espelhamento e a sua elaboração na consciência, devem ser reconhecidas certas propriedades da pedra que a tornam adequada ou inadequada para a atividade pretendida (Lukács, 2013, p. 71).

Embora a pedra, citada por Lukács (2013), permaneça um objeto natural, ela recebe, a partir da ação do homem e da mulher, um pôr socialmente existente no processo de trabalho. Logo, o trabalho afasta as barreiras naturais, sendo um meio de passagem do/a homem/mulher para o estágio de ser social. Destacamos aqui o caráter social do trabalho, uma vez que para que o mesmo possa atingir os fins pretendidos idealmente pelo/a homem/mulher, este deve controlar seus instintos e afetos e 
compreender as suas ações/movimentos, isto é, realizar sobre si o autodomínio. Tal fato não se restringe a formas primitivas do trabalho, mas também ao seu desenvolvimento ulterior. Apesar de este último momento guardar posições teleológicas voltadas mais especificamente a ações dos/as homens/mulheres sobre outros/as homens/mulheres.

O objetivo destas posições teleológicas secundárias já não é mais a transformação direta da natureza, e sim promover intervenções na consciência de outros/as homens/mulheres. Ainda segundo o filósofo húngaro, as posições teleológicas secundárias têm o caráter de práxis social ${ }^{1}$ em seus estágios mais evoluídos. Por isso mesmo, a práxis exibiria em si um grau maior de complexidade, agindo sobre os próprios seres sociais os quais, dotados de consciência, podem mudar os fins idealizados. Isto é, atuar sobre a natureza, que está sujeita às leis naturais e aos acasos, apresentaria menos variabilidades e possibilidades de escolha do que as ações direcionadas aos seres sociais, visto que os homens e as mulheres teriam os seus próprios comportamentos e movimentos favoráveis ou desfavoráveis frente às ações que buscariam o/a influenciar. Observamos, então, que:

Não se trata mais daquele objeto passivo e indiferente à ação teleológica, a causalidade natural; trata-se, agora, de um objeto dotado de consciência, que também põe teleologia. Consequentemente, a objetivação aqui já não trata de moldar o objeto como se o faz no trabalho, mas de induzi-lo a assumir, por si mesmo, determinadas escolhas. O que se pretende com estas atividades é desencadear um processo de criação de disposições afetivas, atitudinais, nos homens que os levem a desenvolver sua atividade sobre o meio (causalidade natural ou social) de uma forma determinada (Macário, 2005, p. 35).

Compreendemos, assim, que no seu sentido ontológico, o trabalho se relaciona diretamente à transformação da natureza, objetivando o novo e com isso se postula como um modelo de práxis social. Entretanto, esta configura um complexo inserido na lógica histórica, social e espiritual dos sujeitos, porquanto orbita nas instituições sociais e sistemas valorativos construídos na sociedade. Queremos dizer que o trabalho é o momento fundante e a práxis social aquilo que é fundado. Ela suscita mediações (complexas) que estão situadas num âmbito tão quão complexo, nas relações humanas, sociais.

Nessa lógica, entendemos a educação como um modelo de práxis social que tem o seu fundamento no trabalho. A atividade educativa se complexifica a partir da relação entre os homens/mulheres; isto significa que a educação possui desdobramentos que vão para além do trabalho, direcionados para a sociedade, num pôr teleológico secundário. Por isso, a educação se mostra como necessária para influenciar/modificar/adequar as ações e pensamentos de outros homens/mulheres. É a partir deste complexo que se torna possível disseminar e controlar modos de vida e comportamentos, bem como ideologias.

A educação faz parte do processo civilizatório e da reprodução social dos sujeitos. As atividades de comunicação, que se dão por meio das linguagens, o surgimento das ciências, da música, por exemplo, são complexos sociais que implicam o desenvolvimento dos indivíduos. Tais complexos, que com o desenvolvimento do trabalho ensejam certa autonomia, serão reproduzidos pelos homens e por mulheres em sua singularidade, o que os/as colocam diante de uma relação reflexiva: ao mesmo tempo em que o indivíduo recebe influências do meio no seu processo de escolhas e decisões, também participa dos rumos e movimentos gerais, genéricos. Observamos, assim, que “. . é preciso ter claro que as escolhas dos indivíduos e, por conseguinte, seus atos, se dão em situações singulares concretas, isto é, elas são circunstanciadas, elas se ligam ao gênero por meio de mediações e não diretamente ..." (Macário, 2005, p. 70).

Nessa perspectiva, a educação, como práxis, está situada no processo das mediações sociais. Este complexo contribui/influencia o momento de escolha dos homens entre as possibilidades e alternativas que lhe são apresentadas.

\footnotetext{
${ }^{1}$ De acordo com Saviani (2017, p. 10), “práxis é um conceito que, embora seja frequentemente considerado como sinônimo de prática, em sentido próprio é um conceito dialético que sintetiza, na forma de superação, os dois elementos contrários representados pela teoria e pela prática. Nesse sentido, a práxis pode ser definida como atividade humana prática fundamentada teoricamente".
} 
Entretanto, por fazer parte de um pôr teleológico de segundo tipo, a educação pode ser base para a afirmação de uma determinada ideologia de dominação. De tal modo:

Quanto mais se desenvolve o trabalho, e com ele a divisão do trabalho, tanto mais autônomas são as formas dos pores teleológicos do segundo tipo, tanto mais eles conseguem se desenvolver como complexo próprio da divisão do trabalho. Essa tendência do desenvolvimento da divisão do trabalho cruza, no plano social, necessariamente com o surgimento das classes; pores teleológicos dessa espécie podem ser colocados espontânea ou institucionalmente a serviço de uma dominação sobre aqueles que por ela são oprimidos, do que provém a tão frequente ligação entre o trabalho intelectual autonomizado e os sistemas de dominação de classe ... (Lukács, 2013, p. 180).

$\mathrm{O}$ desenvolvimento da sociedade e o advento da burguesia exigem que homens e mulheres adequem seus modos de vida às determinações do capital, objetivando a acumulação de lucros e a propriedade privada. Nessa lógica, a educação pode ser um veículo fundamental de controle dos sujeitos para o atendimento das necessidades do capital, nas quais a exploração e a própria captura da criatividade dos homens representam o processo de alienação do trabalho.

No capitalismo acirram-se, assim, as contradições sociais, pois ao mesmo tempo que a educação possibilita a ampliação dos lucros do capital, disciplinando e instrumentalizando o homem e a mulher para a produção de mercadorias, também pode suscitar o conhecimento necessário para que estes/estas possam romper as amarras que os/as subordinam às explorações da sociedade burguesa. Trava-se, nesse momento, no âmbito da educação (pôr teleológico de segundo tipo) o antagonismo entre trabalhadores e grupo dominante: “. . . se a classe trabalhadora luta pela democratização do acesso ao conhecimento produzido pelo conjunto da humanidade ao longo de sua história, a burguesia busca secundarizar a escola esvaziando-a" (Marsiglia et al., 2017, p. 108), transformando a educação e o trabalho em meios de reprodução da lógica competitiva e desumanizadora do capital.

\section{A Relação entre Trabalho e Educação na Sociabilidade Capitalista: Algumas Aproximações}

No contexto do capitalismo, o trabalho e a educação assumem contornos que favorecem a expansão e consolidação desse sistema metabólico. De fato, nele, o trabalho, modelo da práxis social, ganha caracteres que distorcem seu real sentido como categoria fundante do ser social, como atividade criadora e humanizadora, cuja finalidade se encontra na transformação da natureza (teleologia primária) e das relações sociais (teleologia secundária) pelo homem /mulher para a satisfação de suas necessidades. Desse modo, no cenário do capital, o trabalho aparece como mercadoria, cujo proprietário - o/a trabalhador/a - a coloca à disposição dos donos dos meios de produção como uma forma de garantir a sua sobrevivência.

Com o surgimento da propriedade privada dos meios de produção e da divisão social e técnica do trabalho, observamos o afastamento do real significado do trabalho. Ora, no processo de produção, cada vez mais parcelado, em que o/a trabalhador/a se especializa numa tarefa, o/a próprio/a não detém mais o controle e o conhecimento do processo como um todo, em todas as suas etapas, desde o planejamento (momento da prévia-ideação), a apreensão da matéria prima até a finalização do produto. Assim sendo, a fragmentação do processo de trabalho, gesta um tipo de trabalhador/a que não mais se reconhece no produto do seu trabalho. O produto acabado ao final do processo lhe aparece como um objeto estranho, que não lhe pertence, mas a um outro, qual seja, o dono dos meios de produção. Como indica Marx (2010, p. 80), “. . . o objeto que o trabalho produz, o seu produto, se lhe defronta como um ser estranho, como um poder independente do produtor". Mais adiante, o pensador ainda acrescenta:

A exteriorização do trabalhador em seu produto tem o significado não somente de que seu trabalho se torna um objeto, uma existência externa, mas, bem além disso, [que se torna uma existência] que existe fora dele, independente dele e estranha a ele, tornando-se uma potência autônoma diante dele, que a vida que ele concedeu ao objeto se lhe defronta hostil e estranha (Marx, 2010, p. 81, grifos do autor). 
Partindo para a discussão sobre a educação na conjuntura capitalista, podemos questionar qual tipo de relação há entre a educação e a divisão social e técnica do trabalho. Vejamos então que, para além da alienação do trabalho, a divisão social e técnica deste gesta a fragmentação do processo de trabalho, que se torna cada vez mais coletivo, no qual os/as trabalhadores/as detém o controle de apenas uma parcela de todo aquele processo. Nesse movimento, há a distinção entre tarefas mais simples e outras mais complexas, que exigem um grau de conhecimento mais ou menos sofisticado. Do mesmo modo, a hierarquização das tarefas termina por dar origem também à separação entre trabalho manual e intelectual. Este, característico das funções de planejamento, concepção e comando, é reservado aos sujeitos pertencentes à classe dominante; aquele, mais relacionado à função de execução, permanece direcionado à classe trabalhadora.

Sendo assim, é possível percebermos que o tipo de instrução determinada às classes sociais, sob o jugo do sistema do capital, será combinada de acordo com as funções que elas desempenham nessa sociabilidade e de maneira a manter sua hegemonia. Isto é, para a classe dominante gesta-se o conhecimento científico; para a massa trabalhadora, resta-lhes a instrução para o trabalho. Destarte, observamos que a educação a ser desenvolvida estará voltada para a ampliação e consolidação do sistema metabólico do capital, não apenas sob o ponto de vista do fornecimento de conhecimentos necessários à produção material, mas também sob a ótica de disseminar a ideologia legitimadora desse sistema. Mészáros (2008, p. 35) traz à luz essa questão, pontuando que

A educação institucionalizada, especialmente nos últimos 150 anos, serviu - no seu todo - ao propósito de não só fornecer os conhecimentos e o pessoal necessário à máquina produtiva em expansão do sistema do capital, como também gerar e transmitir um quadro de valores que legitima os interesses dominantes.

O modo como o sistema capitalista concebe a proposta educacional, ancora-se na manutenção da sociedade de classes e na exploração da força de trabalho, com vistas à sua expansão ilimitada, requerendo, para isso, a conformação e o envolvimento dos indivíduos nesse projeto de perpetuação da sua hegemonia. Tal ideia vai de encontro ao que Saviani identifica como sendo o objeto da educação. Para este autor, o objeto da educação refere-se “. . . de um lado, à identificação dos elementos culturais que precisam ser assimilados pelos indivíduos da espécie humana para que eles se tornem humanos e, de outro lado e concomitante, à descoberta de formas mais adequadas para atingir esse objetivo" (Saviani, 2000, p. 17).

O filósofo marxista István Mészáros considera que a educação no capitalismo requer a internalização, por parte dos sujeitos, da legitimidade da posição que lhes foi imposta na hierarquia social, combinada com expectativas "adequadas" e formas de conduta "certas", como numa espécie de adestramento dos seus anseios e das suas ações, sendo imprescindível que cada indivíduo adote como suas as metas de reprodução (Mészáros, 2008). Assim, no contexto do capital, os planos e propostas elaborados para a educação convergem para a reprodução de um indivíduo adequado ao projeto de conservação do domínio do sistema.

Dessa maneira, podemos afirmar que as instituições formais de educação têm um importante papel nesse processo de internalização, sendo estas indutoras de uma aceitação dos princípios reprodutivos "orientadores dominantes na própria sociedade, adequados a sua posição na ordem social, e de acordo com as tarefas reprodutivas que lhes foram atribuídas" (Ibidem, p. 44).

Ao trazermos a discussão da estrutura educacional para o cenário do século XXI, observaremos que o projeto de educação corresponde aos parâmetros impostos pelo modelo neoliberal. Neste, a proposta educacional é orientada para alavancar o sistema produtivo, em que a própria elaboração da estrutura e dos conteúdos dos currículos escolares dão ênfase à formação para o trabalho. A concepção neoliberal de educação 
"incorpora em seus fundamentos a lógica do mercado e a função da escola se reduz à formação dos "recursos humanos" para a estrutura de produção. Nessa lógica, a articulação do sistema educativo com o sistema produtivo deve ser necessária. O primeiro deve responder de maneira direta à demanda do segundo" (Bianchetti, 1999, p. 95).

Saviani (2005) assevera que, na conjuntura capitalista contemporânea, os investimentos em educação passaram a ser desejáveis, não apenas por razões sociais ou culturais, mas também por motivos econômicos, pois o retorno desses investimentos tornaram-se tão ou mais compensadores do que aqueles voltados para a produção material.

Dentro dessa dinâmica, a separação entre educação científica e educação profissional, educação intelectual e educação para o trabalho, corrobora para a manutenção da ordem societária capitalista, visto que tal modelo de acepção do conhecimento reverbera na formação de um indivíduo unilateral, com exígua capacidade de crítica e elaboração, pressupostos para a efetivação de uma transformação social. Em contrapartida, a proposta de uma educação que alie os saberes técnicos e científicos, bem como as múltiplas dimensões do humano, da arte, da cultura, da política, que propiciem a formação do indivíduo na sua omnilateralidade, se apresenta como crucial para a construção de uma ordem societária alternativa.

Esse projeto de educação, entretanto, não encontra solo fértil dentro dos limites estabelecidos pela sociedade do capital. Segundo Mészáros (2008), a elaboração de reformas educacionais sob a perspectiva do capital, serviria apenas para legitimar tal ordem sociometabólica. Para além de implementar reformas para corrigir defeitos na sociedade, é imperativo a efetivação de uma mudança estrutural, sem a qual jamais poderemos romper com a lógica de subordinação aos ditames do capitalismo.

Portanto, o papel da educação é soberano, tanto para a elaboração de estratégias apropriadas e adequadas para mudar as condições objetivas de reprodução, como para a automudança consciente dos indivíduos chamados a concretizar a criação de uma ordem social metabólica radicalmente diferente (Mészáros, 2008, p. 65).

Assim sendo, queremos aqui frisar que a educação é mais do que importante para estabelecer uma transformação social, ela é essencial. Romper com a lógica sociometabólica do capital requer exercícios de interpretação e crítica dessa sociabilidade gestada sobre a exploração do homem/mulher e da natureza, exercícios estes associados a um potencial de ação efetiva dos indivíduos na práxis social, forjados sobre um projeto de educação transformadora.

\section{A Educação Capitalista Versus Educação Radical Transformadora: “O que Será que Será”!}

Vimos que a educação se realiza na práxis social, no terreno da reprodução das relações sociais, no contato dos/as homens/mulheres com outros/as homens/mulheres, e que ela passa a fazer parte de interações humanas cada vez mais complexas. A própria dinâmica do trabalho, que consiste na intervenção sobre a natureza, exigiu interatividade, criação e melhoria de instrumentos de trabalho, desenvolvimento do conhecimento sobre matérias-primas e repasse desses saberes. Nessa evolução, a educação passa a não mais se restringir à prática do trabalho.

Como resultado de relações sociais cada vez mais complexas, a educação sofre a influência do tipo de sociedade em que se vive (construídas). As sociedades primitivas não exerciam suas atividades educativas da mesma forma que nas sociedades da Antiguidade. Ainda que muito possivelmente nas sociedades primitivas não se concebesse teoricamente a educação, suas práticas educativas se davam no cotidiano das suas atividades laborativas, na divisão sexual do trabalho, na relação entre gerações etc. Na antiguidade, a exemplo na Grécia, outra configuração se particularizava defronte ao novo modo de produção e distribuição das riquezas.

O surgimento da propriedade privada já traz consigo outra tônica, inclusive por ter estabelecido uma divisão entre trabalho material e trabalho intelectual. Ainda que a educação faça parte das atividades humanas e não podemos dizer que não havia educação nas atividades e relações desenvolvidas entre escravos/as na Grécia, por exemplo, o fato é que se foi cultivando 
uma distância entre quem produz e quem pensa na sociedade. Não por acaso, Sócrates, Platão e Aristóteles se desobrigaram das atividades manuais, destinadas aos/às escravos/as (amparados nessa desigualdade), percorrendo as ruas gregas e filosofando sobre o ser, a existência e outros.

$\mathrm{O}$ que estamos aqui querendo argumentar é que o tipo de sociedade reverbera sobre a educação e suas formas de ser pensada e de existir dentro do quadro de formulações sociais. Na sociedade capitalista não é diferente, assim como não será em outro tipo de sociedade cujas bases não sejam mais a exploração humana ou a existência de classes antagônicas. Na sociedade capitalista, como já abordamos, a alienação ganha todas as dimensões da vida social, inclusive incide sobre a educação, formal e informal, influenciando modos socioculturais de agir e pensar.

Mészáros (2008) argumenta que o capital possui uma lógica incorrigível, ou seja, que não é possível reformá-lo, pois faz parte da sua natureza a imposição de suas determinações estruturais, universalizando-se para o conjunto da sociedade. Limitar, portanto, a educação a essa lógica (sua incontestabilidade) seria negar a necessidade de transformação, de fato, social, que expresse qualitativamente o desenvolvimento da sociedade. Logo mais, seria estreitá-la aos condicionantes interesseiros do capital, não produzindo mudanças realmente transformadoras.

A direção a ser perseguida, ainda conforme o pensador marxista, diz respeito à "mudança educacional radical", que não é possível figurar dentro da institucionalidade desse sistema perverso de acumulação de riquezas e de exercício do controle. A própria educação formal, sinaliza o autor, figurou, nos últimos 150 anos, em benefício da formação de pessoas para operar máquinas (necessidades do capital) e para a manutenção da ordem dominante. Isso se desenvolve não apenas por esta via, das escolas e outras instituições dessa natureza, mas também se dá pela via de internalizações onipresentes externas, espraiando-se pela vida social.

Mészáros (2008) chama a atenção, dessa forma, é para o que Marx e Engels (1982) citam como necessidade da ordem dominante em estabelecer a sua manutenção no poder. Destacam os dois sociólogos:

Cada nova classe, que toma o lugar da outra, antes dela dominante, é obrigada, para alcançar os fins que se propõe, a apresentar seus interesses como sendo o interesse comum de todos os membros da sociedade, isto é, para expressar isso mesmo em termos ideais: é obrigada a emprestar às suas ideias a forma de universalidade, a apresentá-las como sendo as únicas racionais, as únicas universalmente válidas (Marx; Engels, 1984, p. 74).

São construídos, dessa forma, modos de vida materiais e espirituais de legitimação da ordem liberal burguesa, onde se estimulam, tomando por base exemplos práticos da vida cotidiana, o consumismo, o individualismo e a competitividade. Isso tudo, dentro da sistemática perversa das opressões, no contexto de uma sociedade em que "o trabalhador se torna tanto mais pobre quanto mais riqueza produz, quanto mais a sua produção aumenta em poder e extensão. O trabalhador se torna uma mercadoria tão mais barata quanto mais mercadorias cria” (Marx, 2010, p. 80). Quais, portanto, os caminhos para o enfrentamento de tudo isso?

No terreno das ideologias, ainda que haja hegemonia, lida-se com uma disputa, onde convivem outros modos de pensar e valorizar a realidade, gerada no seio das contradições que são sentidas e vividas pelas classes sociais no campo da (re)produção da vida social. Somos sujeitos históricos e, como tais, a ideologia pode ser considerada um modo de consciência na práxis social e, portanto, ser orientada para a superação das opressões e alienações capitalistas. O pensador húngaro, Lukács (2013, p. 476) sinaliza para as mudanças no interior das sociedades:

A história mostra que, na medida em que essa ontologia é carregada por tendências fundamentais da sociedade, muitas vezes ocorre que verdades científicas que a contradizem ricocheteiam impotentes e inefetivas nesse muro da ideologia, mas em outros casos, quando encontramos nela algum apoio, de repente adquirem um ímpeto que arrasa os preconceitos e passam a ocupar o centro da ontologia cotidiana do seu período. 
A educação transformadora, a que tanto reclama Mészáros (2008), se efetiva nesse campo de disputa, ideológico e político, não podendo ser nutrida dentro dos limites da ordem. Os direitos na sociedade capitalista, como o direito à educação, à saúde, ao lazer, à cultura etc. não se efetivam de forma plena, pois assumem uma dimensão abstrata (no plano legal), afinal sua efetivação plena teria que se dar abolindo a estrutura social desigual e tornando homens/mulheres, de fato, livres, em sua liberdade plena, o que só poderá acontecer na práxis social (Marx, 2010). Para isso, devemos romper, de acordo com o marxista, com a lógica do capital.

É importante esclarecermos que, segundo Mészáros (2008), não é pela alternativa da educação formal tal qual está posta hoje que, por si só, se produzirá essa transformação radical, pois esta se constrói na sua capacidade cada vez mais elástica de produção de consenso. As mudanças institucionais isoladas tampouco são capazes de produzir transformações, pois através delas não se reverte o autoritarismo da lógica do próprio capital, afirma Mészáros. A educação, nesse sentido, não comporta a defesa de mudanças graduais ou reformistas, pois elas não se sustentam a longo prazo, tendendo a reabsorver as injunções do capital. Para o marxista, logo mais, o horizonte deve ser o da construção de um outro tipo de sociedade, radicalmente nova.

Um dos elementos abordados pelo filósofo (2008) é a necessidade de enfrentamento do sistema de internalização externo (em suas dimensões visíveis e não visíveis) produzido pelo capitalismo, no qual a educação tem um importante papel a cumprir. A educação é responsável pela produção de uma contraconsciência, desmitificando internalizações enraizadas, na defesa de um outro horizonte, emancipador, como uma alternativa concreta (Mészáros, 2008). E mais, outro elemento relevante é o fato de que se traduz em tarefa indubitável da educação contribuir para se romper com a autoalienação do trabalho (a consciência nos/as trabalhadores/as).

Só para deixarmos ainda mais transparentes os argumentos, a grosso modo, seria a educação como prática capaz de questionar e fazer crítica universal à estrutura, ao antagonismo de classes, à desigualdade produzida por esse sistema, aos seus (des)valores e seu modo liberal de produzir pensamento e ações. Vejamos que, a partir daí, já observamos a dificuldade disso se dar no espaço formal da sala de aula burguesa, sobretudo se se considerar que muito mais do que a crítica, isso deva ocorrer na práxis social, na formulação de um projeto real emancipador, ou seja, no "desenvolvimento contínuo da consciência socialista na sociedade" (Ibidem, p. 79).

A própria relação entre trabalho e educação, na concepção socialista, ganha outra dimensão, sendo impossíveis de serem pensados isoladamente. Assim, não seria cabível uma educação plena, em que não seja conquistado um trabalho realizador, que estimule as potências de realização de cada indivíduo e da coletividade. É tanto que experiências socialistas se deram, nessa área, construindo aliança entre educação e trabalho produtivo, a fim de desconstruir essa divisão entre trabalho material e trabalho intelectual. Uma das teses centrais de Marx, conforme Nogueira (1993), em seus poucos escritos sobre educação, consiste na defesa de uma formação ou ensino aliada com o processo produtivo. Essa tese, obviamente, parte de uma concepção de trabalho pleno, que desenvolva as capacidades valorativas e criativas dos/as trabalhadores/as.

\section{Considerações Finais}

A educação, conforme desenvolvido pelos pensadores marxistas Lukács e Meszáros, é uma atividade ontológica, relativa ao ser social. A partir do trabalho, como categoria fundante do ser social, são desenvolvidos outros complexos sociais que se efetivam na práxis social, no exercício das teleologias secundárias (relação dos/as homens/mulheres com outros homens/mulheres). A educação, e outras categorias (como o direito, a moral, a religião, a filosofia etc.) precipitam o/a homem/mulher para uma cada vez mais extensa, heterogênea e complexa teia de relações sociais: a história!

Nessa perspectiva histórico-crítica, a educação não se resume às instituições escolares, como mormente a concebemos hoje. Ela se opera tanto no sentido estrito, através de sistemas formais, quanto no sentido "lato", na espontaneidade da práxis 
social. O fato é que a educação, que é uma exigência de todo tipo de sociedade (reproduzir determinados conhecimentos, habilidades, conteúdos etc.), quando da emergência da propriedade privada, passa a ser determinada pela distribuição desigual da riqueza material e espiritual. Na sociedade capitalista, isso se acirra e se aprofunda, em função do padrão de acumulação de capital, de sua expansão e em decorrência da sua capacidade amplamente destrutiva.

No capitalismo, conforme Meszáros, a educação passa a ser utilizada como meio para o desenvolvimento de suas forças produtivas, munindo os/as trabalhadores/as de saberes utilitários à manutenção de sua lógica expansionista. Para isso, recorre não apenas às instituições formais, mas, inclusive, faz uso de internalizações onipresentes externas, espraiando-se pela vida social. Uma educação transformadora deve surgir, portanto, na contramão desse sistema (nas suas dimensões visíveis e invisíveis), cumprindo a função de desmitificar a cultura capitalista enraizada no cotidiano da classe trabalhadora e forjando novas bases, na defesa de um outro horizonte, emancipador, como alternativa concreta.

Destarte, não intencionamos que este estudo seja uma contribuição final para as análises sobre a educação. Nosso objetivo, na verdade, é a busca pelo rompimento com o modelo atual que segue os ditames do capital e instrumentaliza a educação, a fimm de manter as relações de poder da classe dominante e o acúmulo de capital.

\section{Referências}

Bianchetti, R. G. (1999). Modelo neoliberal e políticas educacionais. (Coleção Questões da nossa época). (2a ed.), Cortez.

Gil, A. C. (2002). Como elaborar projetos de pesquisa. Atlas.

Kosik, K. (2002). Dialética do Concreto. (7a ed.), Paz e Terra.

Lessa, S. (2015). Para compreender a ontologia de Lukács. (4a ed.), Instituto Lukács.

Lukács, G. (2013). Para uma ontologia do ser social 2. Boitempo.

Macário, E. (2005). Trabalho, reprodução social e educação. 2005. 160 f. Tese. (Doutorado em Educação) - Programa de Pós-Graduação em Educação, Universidade Federal do Ceará, Fortaleza.

Marsiglia, A. C. G., Pina, L. D., Machado, V. de O., \& Lima, M. (2017). A base nacional comum curricular: um novo episódio de esvaziamento da escola no Brasil. Germinal: Marxismo e Educação em debate. (9)1, 107-121.

Marx, K., Engels, F.(1984). A Ideologia Alemã (I - Feuerbach). Hucitec.

Marx, K. (2010). Manuscritos econômico-filosóficos. Boitempo.

Marx, K. (2011). Grundrisse: Manuscritos econômicos de 1857- 1858. Esboços da crítica da economia política. Boitempo.

Mészáros, I. (2008). A educação para além do capital. (2a ed.), Boitempo.

Netto, J. P. (2011). Introdução ao estudo do método de Marx. Expressão Popular.

Nogueira, M. A. (1993). Educação, saber, produção em Marx e Engels. Cortez.

Saviani, D. (2000). Pedagogia histórico-crítica: primeiras aproximações. (7a ed.), Autores Associados.

Saviani, D. (2005). Transformações do capitalismo, do mundo do trabalho e da educação. In: Lombardi, J. C., Saviani, D., Sanf elice, J. L. (orgs.). Capitalismo, trabalho e educação. (3a ed.) Campinas, SP: Autores Associados. p. 13-24.

Saviani, D. (2017). Educação, práxias e emancipação humana. Revista Práxis e Hegemonia Popular, (2)2, 5-20. 